\title{
Fractional-order mathematical model for analysing impact of quarantine on transmission of COVID-19 in India
}

\author{
Pawar D. D. ${ }^{1}$, Patil W. D. ${ }^{2}$, Raut D. K. ${ }^{3}$ \\ ${ }^{1}$ School of Mathematical Sciences, \\ Swami Ramanand Teerth Marathwada University, Nanded-431606, India \\ ${ }^{2}$ Department of Applied Mathematics, \\ A. C. Patil College of Engineering, Navi Mumbai-410210, India \\ ${ }^{3}$ Department of Mathematics, \\ Shivaji Mahavidyalaya, Renapur, Latur-413527, India
}

(Received 6 April 2020; Revised 27 January 2021; Accepted 9 April 2021)

\begin{abstract}
An outbreak of the novel coronavirus disease was first reported in Wuhan, China in December 2019. In India, the first case was reported on January 30, 2020 on a person with a travel history to an affected country. Considering the fact of a heavily populated and diversified country like India, we have proposed a novel fractional-order mathematical model to elicit the transmission dynamics of the coronavirus disease (COVID-19) and the control strategy for India. The classical SEIR model is employed in three compartments, namely: quarantined immigrated population, non-quarantined asymptomatic immigrated population, and local population subjected to lockdown in the containment areas by the government of India to prevent the spread of disease in India. We have also taken into account the physical interactions between them to evaluate the coronavirus transmission dynamics. The basic reproduction number $\left(R_{0}\right)$ has been derived to determine the communicability of the disease. Numerical simulation is done by using the generalised Euler method. To check the feasibility of our analysis, we have investigated some numerical simulations for various fractional orders by varying values of the parameters with help of MATLAB to fit the realistic pandemic scenario.
\end{abstract}

Keywords: COVID-19, epidemic, fractional-order mathematical model (FOMM), reproduction number, generalised Euler method (GEM).

2010 MSC: 34A34, 34A12, 34C05, 92D30, 47H10

DOI: $10.23939 / \mathrm{mmc} 2021.02 .253$

\section{Introduction}

Throughout history, diseases swept the globe, bringing down empires, weakening economies, and changing the course of history. When these infectious diseases exist as epidemics having widespread occurrence, the impact is such appalling that it continues afflicting not only the present but also the future. For instance, the recent coronavirus disease (COVID-19) pandemic has chained the world in shackles with 4307287 positive cases and 295101 deaths reported by May 15, 2020 [1,2]. The first outbreak was reported in Wuhan, China in December 2019 [3,4]. Despite attempted containment measures, the virus spread to other parts of the world, soon resulting in a disastrous pandemic with many countries affected.

The causative agent, the SARS-CoV2 virus is transmitted by coughing, sneezing and close personal contacts such as touching mouth, nose or eyes or shaking hands. The Centers for Disease Control and Prevention(CDCP) reported a wide range of symptoms ranging from mild to severe illness. Cough, shortness of breath, fever, chills, muscle pain, sore throat and new loss of taste or smell are commonly reported symptoms which may appear 2-14 days after exposure to the virus. Other less common symptoms have been reported including gastrointestinal symptoms like nausea, vomiting or diarrhoea. Older adults and people with underlying medical conditions are seen to be at higher risk for developing more serious complications [5]. 
In India, COVID-19 was transmitted through the immigrated population from infected countries. The immigrated population act as a host in this epidemic. As on June 6, 2020, more than 2 lack cases have been confirmed all over India. The variation in rate of infection has been observed due to diverse factors like immigration rate, nature of lock down, population density and awareness, etc. [6].

Scientists and researchers are proposing mathematical models and analyse it using numerical simulation to understand the various aspects of disease transmission. It leads to the roadmap for future strategy of either controlling the spread or recovery of the infected. Victor et al. [7] have framed mathematical model for COVID-19 as a global pandemic and it is predictions. As COVID-19 emerged from China in the end of 2019, Ivorra B., et al. [8]. Tuite Ashleigh R., et al. [9], have demonstrated the pandemic situation of transmission of COVID-19 at Ontario, Canada by defining the appropriate mathematical model. Tian-Mu Chen, et al. [10] have focused on transmissible of COVID-19 by using simulation of mathematical model.

Integer order mathematical models has limitations to analyse complicated real life phenomenons. It is observed that it gives the ideal results and local dynamics. On the contrary, on account of property of memory effect and non-local dynamics, fractional-order model is more efficient than integer order model $[11,12]$. Most of the scientists and researchers have diverted their attention towards fractional calculus to define mathematical models for various diseases and natural phenomenons. Pawar D. D. et al. [13] have proposed fractional-order mathematical model for tuberculosis with two line treatment and analysed it thoroughly by applying generalised Euler method successfully. Kumar Devendra, et al. [14] have proposed fractional-order mathematical model of malaria with anti malarial drug and control strategy for mosquitoes by spraying. Pawar D. D. et al. [15] analise the dynamics of malaria by fractional-order mathematical model. Shaikh, Amjad S. [16] have designed fractional-order mathematical model of COVID-19 transmission taking into account dynamics of transmission and control in India.

Recently, researchers and scientists have formulated fractional-order mathematical models using Atangana-Baleanu derivative which satisfies Lipschitz condition. Khan M. A., et al. [17] have proposed a fractional-order mathematical model for tuberculosis with relapse via Atangana-Baleanu derivative in Caputo sense. Khan et al. [18] have proposed mathematical model of novel coronavirus (2019-nCov) with Atangana-Baleanu fractional derivative by considering bats as a source of infection.

In the current scenario, with no specific drugs or vaccine available, we resorted to control measures as part of our strategy. One such strategy adopted around the world with sketching of many guidelines is quarantine. Quarantine is the separation and restriction of movement or activities of persons who are not ill but are believed to have been exposed to infection, to prevent transmission of disease. The recommended duration of quarantine for COVID-19 based on available information is upto 14 days from the time of exposure.

In the present work, the authors inspect the efficacy of quarantine and asymptomatic nature of the disease as a containment measure in India by formulation of a novel fractional-order mathematical model in the form of a time dependent system of fractional-order differential equations by applying Atangana-Baleanu derivative. The population has been divided into three compartments as local population subject to lockdown by Government of India, immigrated quarantine population and non quarantine immigrated population. The model is imperative for prompt analysis of effectiveness of these measures with consideration of efficacy of quarantine as a containment measure and asymptomatic nature in some individuals.

\section{Preliminaries}

\subsection{Fractional calculus: brief summary}

In this section, we have presented the definitions of fractional derivative and integration, demonstrated by Atangana-Baleanu. 
Definition 1 (Refs. [11], [12]). The Mittag-Leffler function of one parameter is denoted by $E_{\alpha}(z)$ and defined as

$$
E_{\alpha}(z)=\sum_{k=0}^{\infty} \frac{z^{k}}{\Gamma(\alpha k+1)}, \quad \alpha \in C, \quad \operatorname{Re} \alpha>0 .
$$

Definition 2. Atangana-Baleanu fractional-order derivative in Caputo sense [17,18]. Let $g:[a, b] \rightarrow$ $\mathcal{R}$ be a bounded and continuous function then Atangana-Baleanu fractional derivative in Caputo sense of order $0<\alpha \leqslant 1$ is defined as

$$
{ }_{a}^{A B C} D_{t}^{\alpha} g(t)=\frac{M(\alpha)}{(1-\alpha)} \int_{a}^{t} E_{\alpha}\left(-\alpha \frac{(t-q)^{\alpha}}{(1-\alpha)}\right) g^{\prime}(q) d q,
$$

where $\Gamma(\cdot)$ is the gamma function and $M(\alpha)=1-\alpha+\frac{\alpha}{\Gamma(\alpha)}$ is normalisation function.

Definition 3. Atangana-Baleanu fractional-order integral [17,18]. Let $g:[a, b] \rightarrow \mathcal{R}$ be a bounded and continuous function. The corresponding fractional integral concerning to Atangana-Baleanu fractional-order derivative of order $0<\alpha \leqslant 1$ is defined as

$$
{ }_{a}^{A B C} I_{t}^{\alpha} g(t)=\frac{(1-\alpha)}{M(\alpha)} g(t)+\frac{\alpha}{M(\alpha) \Gamma(\alpha)} \int_{a}^{t}(t-q)^{\alpha-1} g(q) d q,
$$

where $M(\alpha)=1-\alpha+\frac{\alpha}{\Gamma(\alpha)}$ is normalisation function.

Theorem 1. For a function $g(t) \in C[a, b]$, the following results holds as in [17, 19]

$$
\left\|{ }_{a}^{A B C} D_{t}^{\alpha} g(t)\right\| \leqslant \frac{M(\alpha)}{(1-\alpha)}\|g(t)\|, \quad \text { where } \quad \| g(t)=\max _{a \leqslant t \leqslant b}|g(t)|,
$$

Further, the Atangana-Baleanu derivative fulfils the Lipschitz condition

$$
\left\|{ }_{a}^{A B C} D_{t}^{\alpha} g_{1}(t)-{ }_{a}^{A B C} D_{t}^{\alpha} g_{2}(t)\right\| \leqslant L\left\|g_{1}(t)-g_{2}(t)\right\|,
$$

where $0<\alpha \leqslant 1$ is the order of fractional derivative.

Theorem 2. Atangana-Baleanu type fractional-order differential equation defined as follows

$$
{ }_{a}^{A B C} D_{t}^{\alpha} g(t)=F(t)
$$

has the unique solution [17] as

$$
g(t)=\frac{(1-\alpha)}{M(\alpha)} F(t)+\frac{\alpha}{M(\alpha) \Gamma(\alpha)} \int_{a}^{t}(t-q)^{\alpha-1} F(q) d q .
$$

\subsection{Analysis of generalised Euler method [GEM]}

In this section, we are presenting extension of generalised Euler method as explained in [13] for the system of fractional order ' $n$ ', the number of linear and non-linear differential equations as

$$
a D_{t}^{\alpha} y_{i}(t)=f_{i}\left(t, y_{1}(t), y_{2}(t), y_{3}(t), \ldots, y_{n}(t)\right), \quad 0<\alpha \leqslant 1, \quad t>0,
$$

with the initial conditions $y_{i}(0)=y_{i_{0}}$ for $i=1,2,3, \ldots, n$.

We have to find the solution in the finite interval $[0, a]$. Assume that $y_{i}(t), D_{a}^{\alpha} y_{i}(t), \ldots$ are continuous on $[0, a]$ for all $i=1,2,3, \ldots, n$. The formula for generalised Euler method (GEM) For $t_{j+1}=t_{j}+h$ for all $j=0,1,2,3, \ldots, k$ such that $h$ is sufficiently small is 


$$
y_{i}\left(t_{j+1}\right)=y_{i}\left(t_{j}\right)+f_{i}\left(t, y_{1}\left(t_{j}\right), y_{2}\left(t_{j}\right), y_{3}\left(t_{j}\right), \ldots, y_{n}\left(t_{j}\right)\right) \frac{h^{\alpha}}{\Gamma(\alpha+1)}
$$

for all $i=1,2, \ldots, n$.

\section{Fractional-order model formulation}

In this section, the authors have analyzed the efficacy of quarantine as a containment measure with infection by using the proposed novel fractional-order mathematical model of transmission control of COVID-19. The biological characteristics of the disease have been considered in detail to effectively design this model such that optimum possible vectors are formulated for the designated classes. The construction of the model is explained in the current section.

The proposed model is a simulation of the SEIR (Susceptible-Exposed-Infected-Recovered) model in epidemiology. We have considered the immigrated population as the source of disease. It is further divided into two compartments - one is quarantined and the other is non-quarantined. A separate compartment with the local population subjected to lockdown by the government of India is also taken into consideration. By extrapolating the SEIR model to the three formulated compartments, the total population is taken as $\Lambda$ of the containment region, and further this population is divided into ten classes as follows:

i) Susceptible class, $S_{l}(t)$, denotes susceptible local population with no travel history with the probability of recruitment ' $\sigma$ '. Those from the immigrated compartment are classified into the quarantined immigrated susceptible population and the non-quarantined immigrated susceptible population denoted by $S_{q m}(t)$ and $S_{n q m}(t)$, respectively. The rates of recruitment to $S_{q m}(t)$ and $S_{n q m}(t)$ are $\sigma_{1}$ and $\sigma_{2}$ respectively.

ii) Exposed class. On assumption of exposure to the virus, the individuals from the susceptible class move to the exposed classes. $E_{l}(t)$ indicates the exposed local population with the probability of recruitment ' $e_{l}$ '. For those from the compartments of quarantined immigrated exposed population and non-quarantined immigrated exposed population are indicated by $E_{q m}(t)$ and $E_{n q m}(t)$ respectively. The rates of recruitment to $E_{q m}(t)$ and $E_{n q m}(t)$ are $\beta_{1}$ and $\beta_{2}$, respectively. These individuals are asymptomatic and will be in the incubation period and can be moved to the infected class.

iii) Infected class. This class includes the symptomatic individuals that are presenting clinical signs. $I_{l}(t)$ denotes the exposed local population with the probability of recruitment ' $i_{l}$ '. For those from the immigrated compartments: quarantined immigrated exposed population and non-quarantined immigrated exposed population are denoted by $I_{q m}(t)$ and $I_{n q m}(t)$ respectively. The rates of recruitment to $I_{q m}(t)$ and $I_{n q m}(t)$ are $\gamma_{1}$ and $\gamma_{2}$, respectively.

iv) Recovered class. $R(t)$ includes individuals who have recovered from the disease from all the compartments. The rate of recruitment to the recovered class from $I_{q m}(t), I_{n q m}(t)$ and $I_{l}(t)$ are $\delta_{1}, \delta_{2}$ and $r_{l}$, respectively.

The following conditions are also contemplated in the construction of this model:

1. The recruitment rates of individuals including births are assumed to be constant.

2. Individuals in all classes have a natural rate of mortality $d$. Those in the infected class with disease-induced deaths owing to age or other comorbidities are denoted by $d_{i d}$.

3. We have assumed that not all individuals exposed to the virus will develop the symptomatic disease. Such individuals as in $E_{q m}(t)$ and $E_{n q m}(t)$ will directly shift to the recovered class with the rates $r_{1}$ and $r_{2}$, respectively.

4. Existence of physical contacts and interactions between immigrated non-quarantined and local populations contributes dramatically to the transfer of the disease to the local population.

5. The exposed local population gets transferred to the compartment of the non-quarantined immigrated exposed population with the rate $e_{l n q}$. 
6. Those who are quarantined, strictly and diligently follow it hereby eliminating the possibility of transmission to others.

7. The non-quarantined immigrated and local populations are asymptomatic as per the observations, they do not show any symptoms but facilitate spread of disease.

Thus, $N(t)$ denotes the total number of individuals in population such that $N(t)=S_{q m}(t)+$ $E_{q m}(t)+I_{q m}(t)+S_{n q m}(t)+E_{n q m}(t)+I_{n q m}(t)+S_{l}(t)+E_{l}(t)+I_{l}(t)+R(t)$. Let $c_{n q m e l}$ be the probability that non-quarantined individuals in incubation period come in contact with local susceptible individuals. The rate of infection to local susceptible individuals from non-quarantined in incubation period individuals denoted by ' $k_{n q m e l}$ ' is

$$
k_{n q m e l}=c_{n q m e l} n_{b} T_{b} \frac{E_{n q m}}{N} .
$$

Let $C_{n q m i l}$ be the probability that non-quarantined infected individuals come in contact with local susceptible individuals. The rate of infection to local susceptible individuals from non-quarantined infected individuals denoted by ' $k_{n q m i l}$ ' is

$$
k_{n q m i l}=C_{n q m i l} n_{b} T_{b} \frac{I_{n q m}(t)}{N(t)},
$$

where ' $n_{b}^{\prime}$ is the average number of local individuals being in contact with non-quarantine immigrated for the period ' $T$ '.

Let $C_{l e l}$ be the probability that local susceptible individuals come in contact with local exposed individuals. The rate of infection to local susceptible individual from local exposed individual denoted by ' $k$ lel' is

$$
k_{l e l}=C_{l e l} n_{a} T_{a} \frac{E_{l}(t)}{N(t)} .
$$

Let $C_{l i l}$ be the probability that local infected individuals come in contact with local susceptible individuals. The rate of infection to local susceptible individuals from local infected individuals denoted by ' $k$ lil' is

$$
k_{l i l}=C_{l i l} n_{a} T_{a} \frac{I_{l}(t)}{N(t)}
$$

where ' $n_{a}$ ' is the average number of local susceptible individuals coming in contact with local infected individuals for the period ' $T_{a}$ '. The total rate of coronavirus transfer from local susceptible to local exposed population is ' $e_{l}$ ' and it is given by

$$
e_{l}=k_{l e l}+k_{l i l}+k_{n q m i l}+k_{n q m e l} .
$$

The fractional-order system of differential equations that defines the proposed model of COVID-19 is given as follows

$$
\begin{aligned}
& { }_{a}^{A B C} D_{t}^{\alpha} S_{l}(t)=\sigma \Lambda-\left(e_{l}+d\right) S_{l}(t), \\
& { }_{a}^{A B C} D_{t}^{\alpha} E_{l}(t)=e_{l} S_{l}(t)-\left(i_{l}+e_{l n q}+d\right) E_{l}(t), \\
& { }_{a}^{A B C} D_{t}^{\alpha} I_{l}(t)=i_{l} E_{l}(t)-\left(r_{l}+d_{i d}\right) I_{l}(t), \\
& { }_{a}^{A B C} D_{t}^{\alpha} S_{q m}(t)=\sigma_{1} \Lambda-\beta_{1} S_{q m} I_{q m}(t)-d S_{q m}(t), \\
& { }_{a}^{A B C} D_{t}^{\alpha} E_{q m}(t)=\beta_{1} S_{q m}(t) I_{q m}-\left(\gamma_{1}+r_{1}+d\right) E_{q m}(t), \\
& { }_{a}^{A B C} D_{t}^{\alpha} I_{q m}(t)=\gamma_{1} E_{q m}(t)-\left(\delta_{1}+d_{i d}\right) I_{q m}(t), \\
& { }_{a}^{A B C} D_{t}^{\alpha} S_{n q m}(t)=\sigma_{2} \Lambda-\beta_{2} S_{n q m}(t) I_{n q m}(t)-d S_{n q m}(t),
\end{aligned}
$$




$$
\begin{aligned}
& { }_{a}^{A B C} D_{t}^{\alpha} E_{n q m}(t)=\beta_{2} S_{n q m}(t) I_{q m}(t)+e_{l n q} E_{l}(t)-\left(\gamma_{2}+r_{2}+d\right) E_{n q m}(t), \\
& { }_{a}^{A B C} D_{t}^{\alpha} I_{n q m}(t)=\gamma_{2} E_{n q m}(t)-\left(\delta_{2}+d_{i d}\right) I_{n q m}(t), \\
& \underset{a}{A B C} D_{t}^{\alpha} R(t)=r_{1} E_{q m}(t)+r_{2} E_{n q m}+\delta_{1} I_{q m}+\delta_{2} I_{n q m}+r_{l} I_{l}-d R(t),
\end{aligned}
$$

where $0<\alpha \leqslant 1$ is the order of fractional derivative and we obtain integer order model at $\alpha=1$. The classes of the model have respective initial conditions as mentioned in numerical analysis.

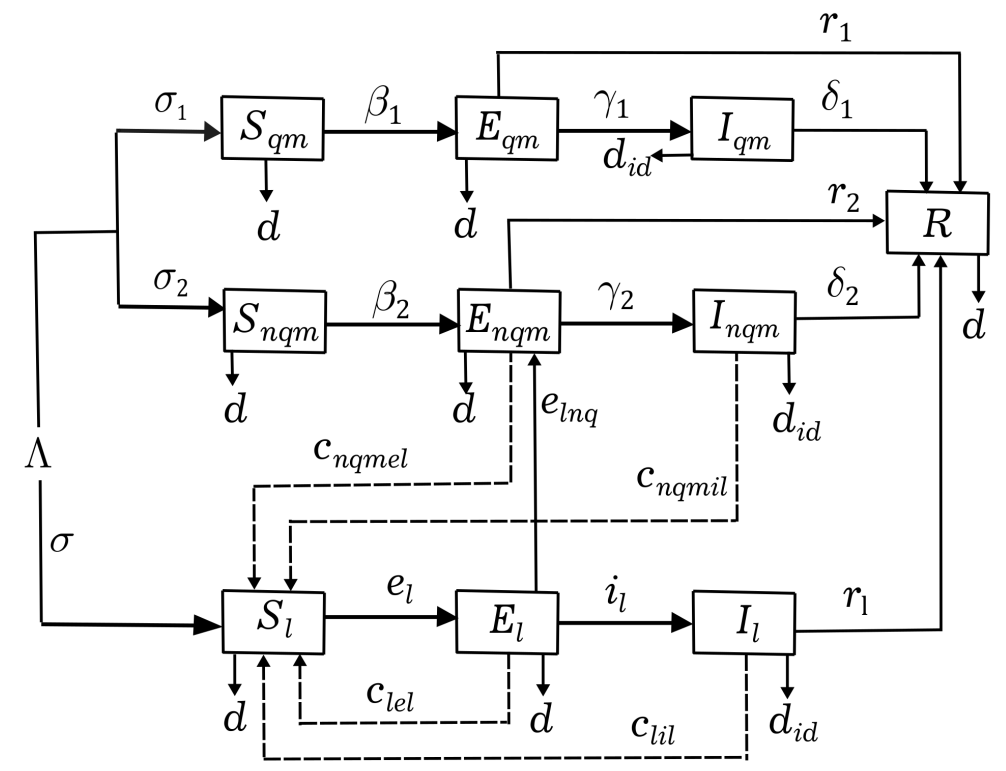

Fig. 1. A schematic flow chart of dynamics of transmission of coronavirus disease (COVID19) along with the direction of infection represented by dash line.

\subsection{Mathematical analysis of the model}

In this section, we have performed some mathematical analysis of the model to study some of the biological and mathematical properties of the model. Here, we define a set of vectors [17] of all the classes of the model as

$$
\begin{aligned}
\triangle= & \left\{\left(S_{l}, E_{l}, I_{l}, R, S_{q m}, E_{q m}, I_{q m}, S_{n q m}, E_{n q m}, I_{n q m}\right) \in R_{+}^{10}: S_{l}+E_{l}+I_{l}+R+S_{q m}+E_{q m}\right. \\
& \left.+I_{q m}+S_{n q m}+E_{n q m}+I_{n q m} \leqslant \frac{\left(\sigma+\sigma_{1}+\sigma_{2}\right) \Lambda}{d}\right\} .
\end{aligned}
$$

The above set ' $\triangle$ ' proves that the dynamics of COVID-19 transmission is biologically well defined.

\subsubsection{Non-negative solution}

The positivity of the proposed model has been derived as follows:

Lemma 1. The closed set such that $\triangle=\left\{\left(S_{l}, E_{l}, I_{l}, R, S_{q m}, E_{q m}, I_{q m}, S_{n q m}, E_{n q m}, I_{n q m}\right) \in\right.$ $\left.R_{+}^{10}: S_{l}+E_{l}+I_{l}+R+S_{q m}+E_{q m}+I_{q m}+S_{n q m}+E_{n q m}+I_{n q m} \leqslant \frac{\left(\sigma+\sigma_{1}+\sigma_{2}\right) \Lambda}{d}\right\}$ is positively invariant with respect to (8).

Proof. The Atangana-Baleanu Caputo-sense derivative of the total population $N(t)$ is

$$
\begin{aligned}
{ }_{a}^{A B C} D_{t}^{\alpha} N(t)= & \left(\sigma+\sigma_{1}+\sigma_{2}\right) \Lambda-d\left(S_{l}(t)+S_{q m}(t)+S_{n q m}(t)+E_{l}(t)\right. \\
& \left.+E_{q m}(t)+E_{n q m}(t)+R(t)\right)-d_{i d}\left(I_{l}(t)+I_{q m}(t)+I_{n q m}(t)\right) \\
\leqslant & \left(\sigma+\sigma_{1}+\sigma_{2}\right) \Lambda-d N(t) .
\end{aligned}
$$


Performing the Laplace transform of (10)

$$
\begin{aligned}
N(t) \leqslant & \left(\frac{\beta(\alpha)}{\beta(\alpha)+(1-\alpha) d} N(0)+\frac{(1-\alpha)\left(\sigma+\sigma_{1}+\sigma_{2}\right) \Lambda}{\beta(\alpha)+(1-\alpha) d}\right) E_{\alpha, 1}\left(-\beta t^{\alpha}\right) \\
& +\frac{\alpha\left(\sigma+\sigma_{1}+\sigma_{2}\right) \Lambda}{\beta(\alpha)+(1-\alpha) d} E_{\alpha, \alpha+1}\left(-\beta t^{\alpha}\right),
\end{aligned}
$$

where $\beta=\frac{\alpha d}{\beta(\alpha)+(1-\alpha) d}$ and $E_{a, b}(x)$ is the Mittag-Leffler function of $x$ with two parameters of ' $a$ ' and ' $b$ ' as defined above. As Mittag-Leffler function has asymptomatic behaviour [17]. Therefore, it obviously proves that $N(t) \leqslant \frac{\Lambda}{d}$ by taking limit $t \rightarrow \infty$.

Thus the solution of the model exists in $\triangle$ and it proves the positivity for all the solutions in the region $\triangle$ defined in $R_{+}^{10}$ for the model.

\subsubsection{Equilibrium points}

In order to obtain the equilibrium points of the model which is the system of differential equations, we have to equate all the equations to ' 0 '. So,

$$
\begin{aligned}
{ }_{a}^{A B C} D_{t}^{\alpha} S_{l}(t) & ={ }_{a}^{A B C} D_{t}^{\alpha} E_{l}(t)={ }_{a}^{A B C} D_{t}^{\alpha} I_{l}(t)={ }_{a}^{A B C} D_{t}^{\alpha} R(t)={ }_{a}^{A B C} D_{t}^{\alpha} S_{q m}(t)=0, \\
{ }_{a}^{A B C} D_{t}^{\alpha} E_{q m}(t) & ={ }_{a}^{A B C} D_{t}^{\alpha} I_{q m}(t)={ }_{a}^{A B C} D_{t}^{\alpha} S_{n q m}(t)={ }_{a}^{A B C} D_{t}^{\alpha} E_{n q m}(t)={ }_{a}^{A B C} D_{t}^{\alpha} I_{n q m}(t)=0
\end{aligned}
$$

by solving all these equations, we get the disease free equilibrium as

$$
\begin{aligned}
X_{0} & =\left(S_{l}, E_{l}, I_{l}, R, S_{q m}, E_{q m}, I_{q m}, S_{n q m}, E_{n q m}, I_{n q m}\right) \\
& =\left(\frac{\sigma \Lambda}{d}, 0,0,0, \frac{\sigma_{1} \Lambda}{d}, 0,0, \frac{\sigma_{2} \Lambda}{d}, 0,0\right) .
\end{aligned}
$$

\subsubsection{Basic reproduction number}

To determine the growth of infection among population, we need to compute the basic reproduction number by using next generation matrix method [17]. The special matrix ' $F$ ' gives us the newly infected cases generated by a single infected individual present in the model in the susceptible population and the remaining terms present in the model are carried out as the terms of another matrix ' $V$ '. The spectral radius of $F V^{-1}$ gives the basic reproduction number of the model,

$$
F=\left[\begin{array}{cccccc}
C_{l e l} n_{a} T_{a} & C_{l i l} n_{a} T_{a} & 0 & 0 & C_{n q m e l} n_{b} T_{b} & C_{n q m i l} n_{b} T_{b} \\
0 & 0 & 0 & 0 & 0 & 0 \\
0 & 0 & 0 & \beta_{1} & 0 & 0 \\
0 & 0 & 0 & 0 & 0 & 0 \\
0 & 0 & 0 & 0 & 0 & \beta_{2} \\
0 & 0 & 0 & 0 & 0 & 0
\end{array}\right]
$$

and

$$
V=\left[\begin{array}{cccccc}
\left(i_{l}+e_{l n q}+d\right) & 0 & 0 & 0 & 0 & 0 \\
-i_{l} & \left(r_{l}+d_{i d}\right) & 0 & 0 & 0 & 0 \\
0 & 0 & \left(\gamma_{1}+r_{1}+d\right) & 0 & 0 & 0 \\
0 & 0 & -\gamma_{1} & \left(\delta_{1}+d i d\right) & 0 & 0 \\
-e_{l n q} & 0 & 0 & 0 & \left(\gamma_{2}+r_{2}+d\right) & 0 \\
0 & 0 & 0 & 0 & -\gamma_{2} & \left(\delta_{2}+\text { did }\right)
\end{array}\right]
$$

The spectral radius of $A=F . V^{-1}$ gives the reproduction number $\left(R_{0}\right)$. Numerical values of reproduction number has been calculated with the help of MATLAB for every set of values of parameters. 


\subsubsection{Existence and uniqueness of solution of the model}

In view of crucial role of existence and uniqueness of solution in the analysis of mathematical model of natural phenomenon, we have examined existence and uniqueness of solution of fractional-order mathematical model with exponential law by using fixed point theory.

Now we apply fractional integral operator (2) to the mathematical model. For further understanding, the mathematical model can be written as

$$
\begin{aligned}
{ }_{a}^{A B C} D_{t}^{\alpha} Y(t) & =F(t, Y(t)), \\
Y(0) & =Y_{0}, \quad 0<t<T<\infty .
\end{aligned}
$$

Where, $Y(t)=\left(S_{l}(t), E_{l}(t), I_{l}(t), R(t), S_{q m}(t), E_{q m}(t), I_{q m}(t), S_{n q m}(t), E_{n q m}(t), I_{n q m}(t)\right)^{T}$. The function $F: R_{+} \times R_{+}^{10} \rightarrow R_{+}^{10}$ is $C^{\infty}\left(R_{+}^{10}\right)$.

Let us take initial condition for all classes as

$$
Y_{0}(t)=\left(S_{l}(0), E_{l}(0), I_{l}(0), R(0), S_{q m}(0), E_{q m}(0), I_{q m}(0), S_{n q m}(0), E_{n q m}(0), I_{n q m}(0)\right)^{T} .
$$

As Atangana-Baleanu derivative satisfies Lipschitz condition, as

$$
\left\|F\left(t, Y_{2}(t)\right)-F\left(t, Y_{2}(t)\right)\right\| \leqslant N\left\|Y_{2}(t)-Y_{1}(t)\right\| .
$$

Theorem 3 (Ref. [17]). Fractional order model involving Atangana-Baleanu fractional-order derivative of Caputo sense (2) has a unique solution such that

$$
\frac{(1-\alpha)}{M(\alpha)} b+\frac{1}{\Gamma(\alpha) M(\alpha)} b\left(T_{\max }\right)^{\alpha}<1 .
$$

Proof. Applying Atangana-Baleanu fractional integral (3) to both sides of (12), gives rise to Voltera integral equation as

$$
Y(t)=Y_{0}+\frac{(1-\alpha)}{M(\alpha)} F(t, Y(t))+\frac{\alpha}{\Gamma(\alpha) M(\alpha)} \int_{0}^{t} F(\psi, Y(\psi))(t-\psi)^{\alpha-1} d \psi
$$

Let $J=(0, T)$ and take a operator $\Omega: C\left(J, R^{10}\right) \rightarrow C\left(J, R^{10}\right)$ defined as

$$
\Omega(t)[Y(t)]=Y_{0}+\frac{(1-\alpha)}{M(\alpha)} F(t, Y(t))+\frac{\alpha}{\Gamma(\alpha) M(\alpha)} \int_{0}^{t} F(\psi, Y(\psi))(t-\psi)^{\alpha-1} d \psi
$$

By taking spectrum norm on $J$, as $\|\cdot\|_{J}=\sup _{t \in J}\|Y(t)\|, Y(t) \in C$. As $C\left(J, R^{10}\right)$ and $\|\cdot\|_{J}$ construct a Banach space.

We have

$$
\begin{aligned}
\| \Omega\left[Y_{2}(t)\right]-\Omega\left[Y_{1}(t) \|_{j}=\right. & \| \frac{(1-\alpha)}{M(\alpha)}\left(F\left(t, Y_{2}(t)\right)-F\left(t, Y_{1}(t)\right)\right) \\
& +\frac{\alpha}{\Gamma(\alpha) M(\alpha)} \int_{0}^{t}\left(F\left(\psi, Y_{2}(\psi)\right)-F\left(\psi, Y_{1}(\psi)\right)\right)(t-\psi)^{\alpha-1} d \psi \|_{j}
\end{aligned}
$$

Applying Lipschitz condition

$$
\left\|\Omega\left[Y_{2}(t)\right]-\Omega\left[Y_{1}(t)\right]\right\| \leqslant\left(\frac{(1-\alpha)}{M(\alpha)} B+\frac{B}{\Gamma(\alpha) M(\alpha)} T_{\max }^{\alpha}\right)\left\|Y_{2}(t)-Y_{1}(t)\right\|_{j} .
$$

Hence it deduce that

$$
\left\|\Omega\left[Y_{2}(t)\right]-\Omega\left[Y_{1}(t)\right]\right\| \leqslant b\left\|Y_{2}(t)-Y_{1}(t)\right\|_{j} .
$$

We conclude that we obtain the uniqueness of the solution of the model.

Mathematical Modeling and Computing, Vol. 8, No. 2, pp. 253-266 (2021) 


\section{Numerical analysis and description}

In this section, numerical analysis of results are represented in the form of graphs using MATLAB. The authors believe, it is of great importance that numerical analysis is based on real-time situations in the world for estimation to be feasible and accurate. The main purpose of such analysis for an epidemic model is to investigate the dominant features associated with certain interventions which greatly affects the disease dynamics. As the data is not available to define the values of parameters, we have done various possible combinations of parameters by using least square fitting technique to estimate close to real-world situations and a variety of results.

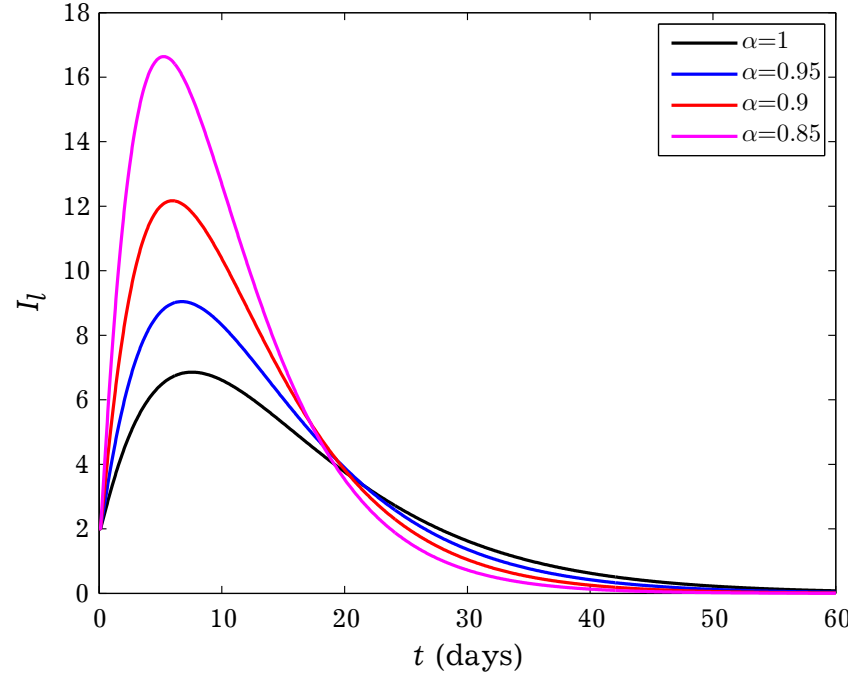

$\boldsymbol{a}$ Numerical analysis of infected local population.

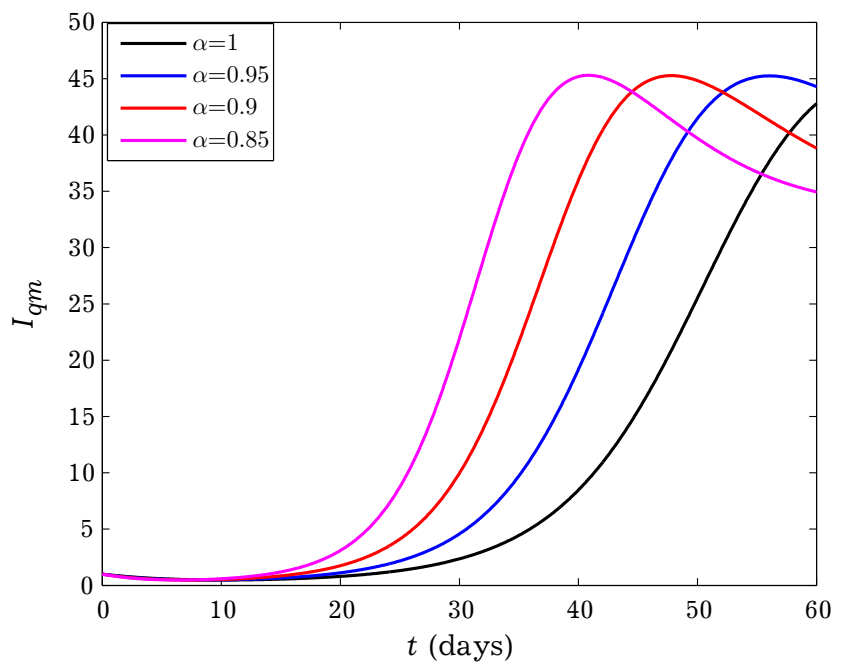

c Numerical analysis of infected quarantine migrated population.

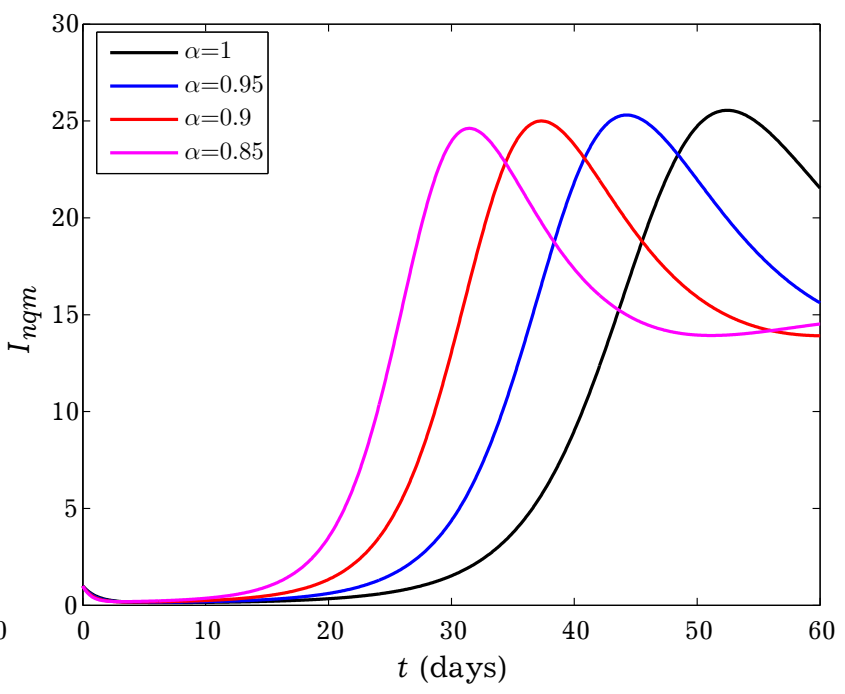

$\boldsymbol{b}$ Numerical analysis of infected non quarantine migrated and asymptomatic local population.

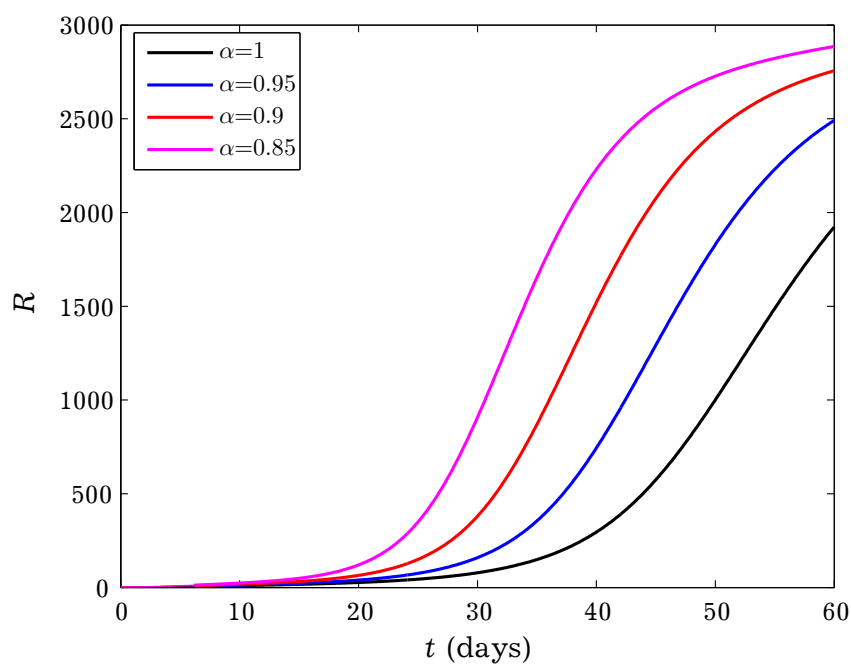

$\boldsymbol{d}$ Numerical analysis of recovered population.

Fig. 2. Analysis of infected and recovery type of classes with values of parameters $\sigma=0.25, \Lambda=500000$, $d=2 / 69.5, i_{l}=0.09, r_{l}=4 / 122, d_{i d}=4 / 122, r_{1}=0.09, r_{2}=0.06, \delta_{1}=0.09, \delta_{2}=0.8, \sigma_{1}=0.0002$, $\sigma_{2}=0.00008, \beta_{1}=0.00567, \beta_{2}=0.00764, \gamma_{1}=0.006, \gamma_{2}=0.056, C_{\text {nqmel }}=0.00021, C_{\text {nqmil }}=0.00012$, $C_{l e l}=0.41, C_{l i l}=0.032, n_{a}=1.5, n_{b}=1.65, T_{a}=0.7, T_{b}=0.56, e_{l n q}=0.008$ and $S_{l}(0)=4, I_{l}(0)=2$, $E_{l}(0)=3, S_{q m}(0)=2, E_{q m}(0)=1, I_{q m}(0)=1, S_{n q m}(0)=3, E_{n q m}(0)=2, I_{n q m}(0)=1, R(0)=2$, $R_{0}=4.0128$. 


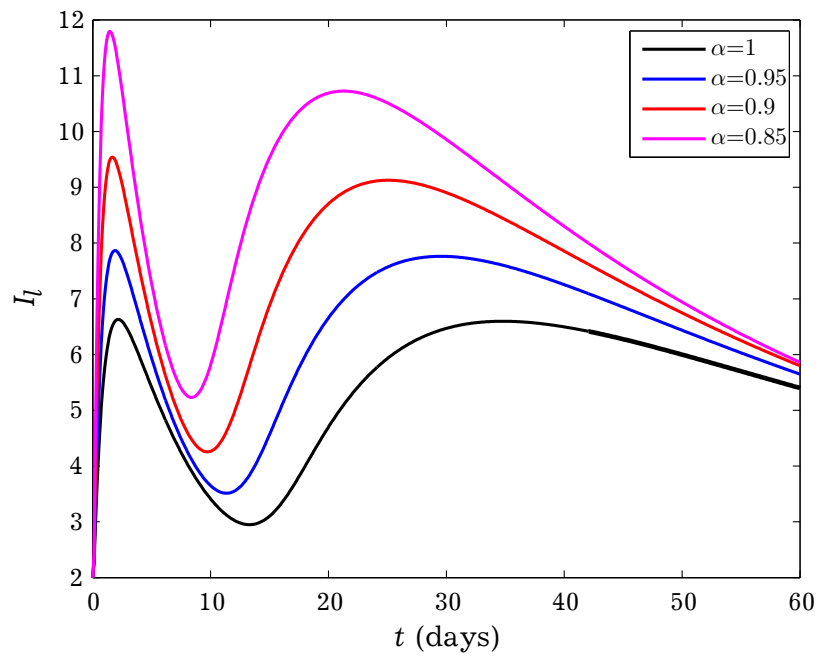

$\boldsymbol{a}$ Numerical analysis of infected local population.

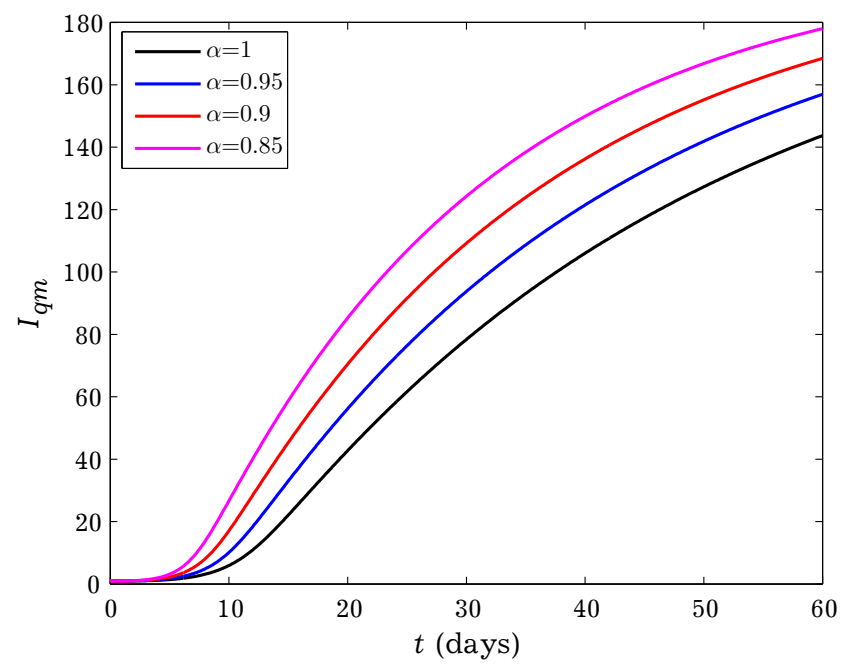

c Numerical analysis of infected quarantine migrated population.

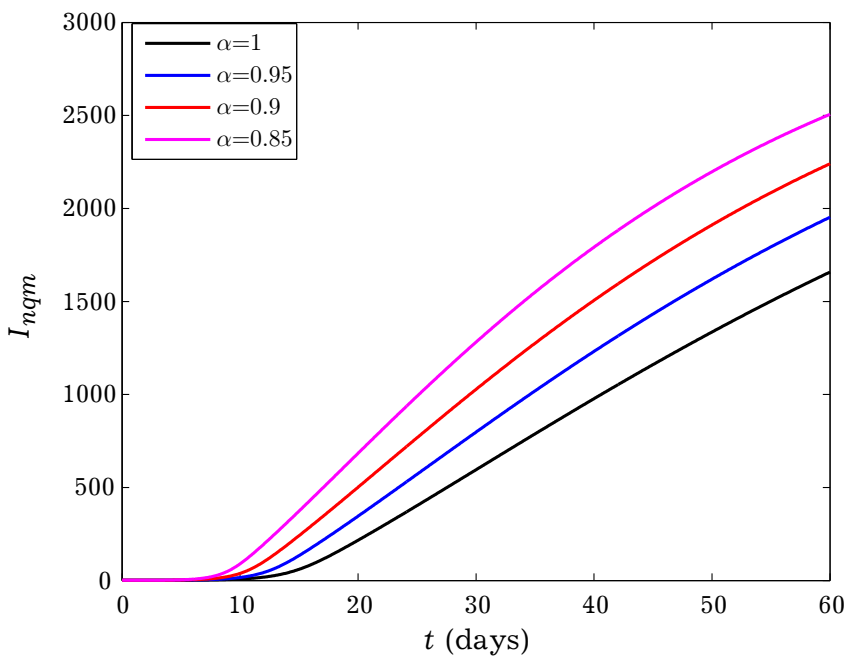

$\boldsymbol{b}$ Numerical analysis of infected non quarantine migrated and asymptomatic local population.

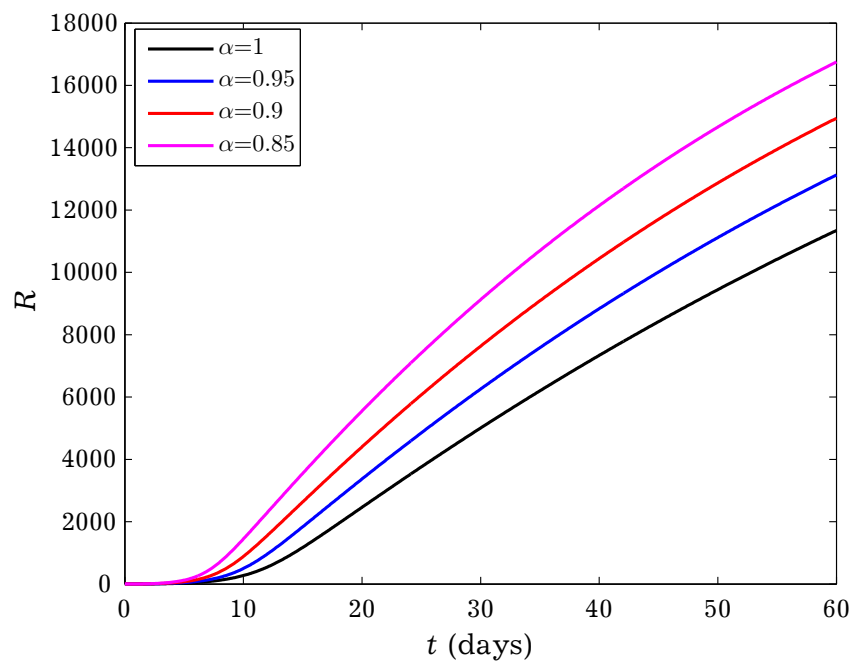

$\boldsymbol{d}$ Numerical analysis of recovered population.

Fig. 3. Analysis of infected and recovery type of classes with values of parameters $\sigma=0.25, \Lambda=500000$, $d=1 / 69.5, i_{l}=0.8, r_{l}=1 / 122, d_{i d}=2 / 122, r_{1}=0.09, r_{2}=0.009, \delta_{1}=0.009, \delta_{2}=0.009, \sigma_{1}=0.0006$, $\sigma_{2}=0.0006, \beta_{1}=0.0567, \beta_{2}=0.00964, \gamma_{1}=0.0018, \gamma_{2}=0.009, C_{n q m e l}=0.21, C_{n q m i l}=0.21, C_{\text {lel }}=0.31$, $C_{l i l}=0.32, n_{a}=0.85, n_{b}=0.9, T_{a}=0.7, T_{b}=0.6, e_{l n q}=0.3$ and initial values $S_{l}(0)=4, S_{q m}(0)=3$, $\operatorname{Snqm}(0)=2, E_{l}(0)=3, E_{q m}(0)=2, E_{n q m}(0)=1, I l(0)=2, I_{q m}(0)=1, I_{n q m}(0)=1, R(0)=2$ and $R_{0}=3.8247$.

The authors have graphically represented 3 sets of numerical simulations obtained based on integration of realistic information and certain estimations of initial conditions and parameters. We have come across a good agreement between the reported data from various locations in India and some estimations of the other components. While estimating the parameters used in the enumerated figures, we observed the simulation results with the help of MATLAB for multiple set of parameters. After that we have selected from these which are parallel between case formulation and available real life field data in the containment area in India. For each set of values of parameters and initial values of classes, the reproduction number is also calculated.

We have estimated the total population as 5,00,000 considering the average population of containment areas and the average mortality rate in India to be $d=1 / 69.50$ per year [16]. We have the time level up to 60 days for the numerical simulation. 


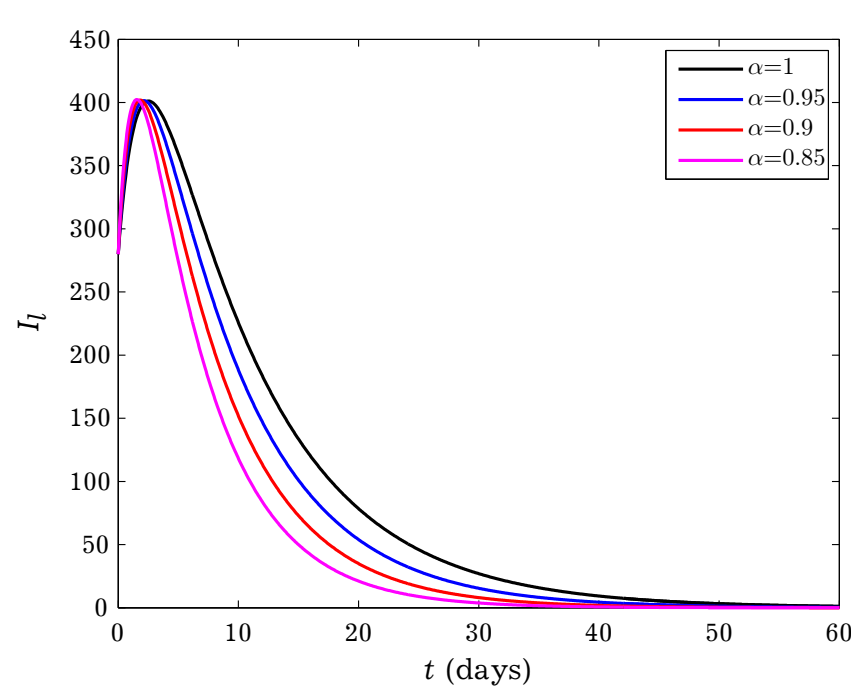

$\boldsymbol{a}$ Numerical analysis of infected local population.

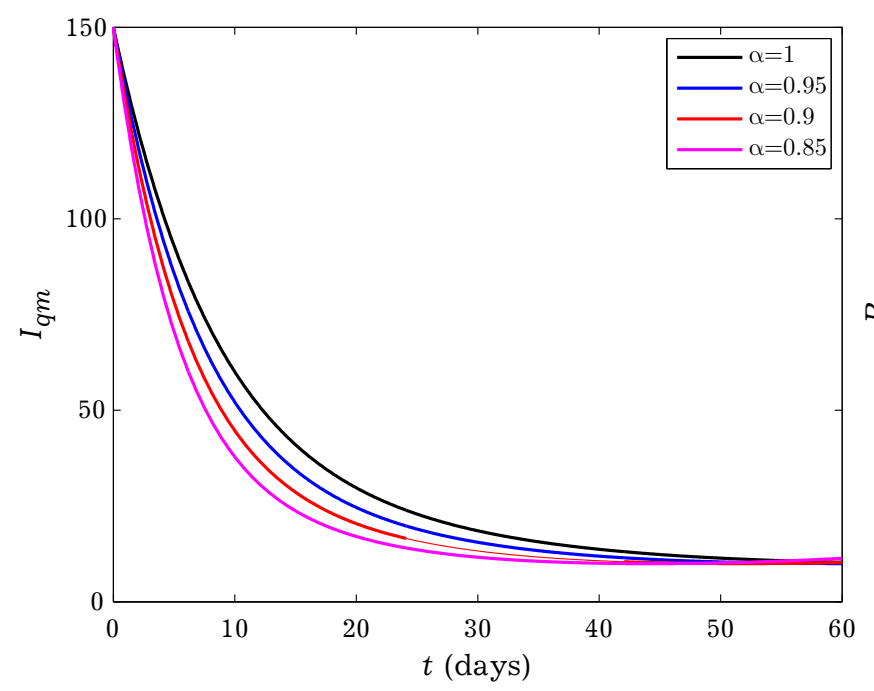

c Numerical analysis of infected quarantine migrated population.

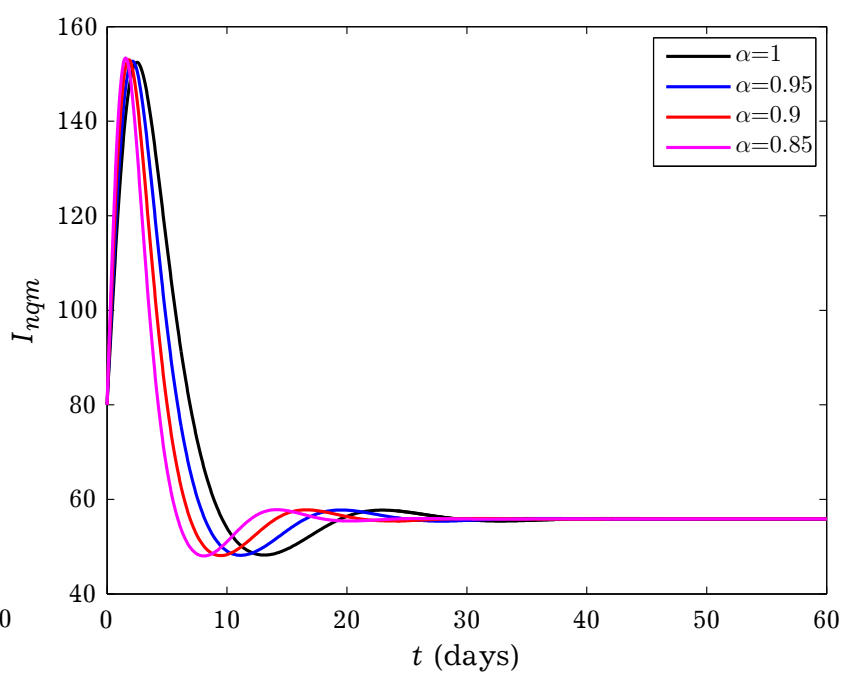

$\boldsymbol{b}$ Numerical analysis of infected non quarantine migrated and asymptomatic local population.

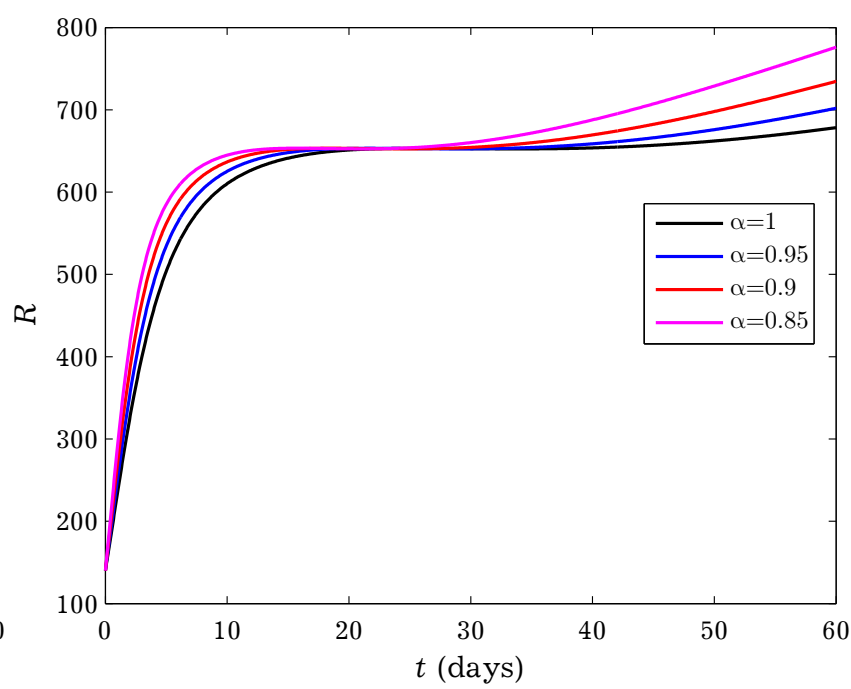

$\boldsymbol{d}$ Numerical analysis of recovered population.

Fig. 4. Analysis of infected and recovery type of classes with values of parameters $\sigma=0.0025, \Lambda=500000$, $d=1 / 69.5, i_{l}=0.4, r_{l}=1 / 122, d_{i d}=2 / 122, r_{1}=0.09, r_{2}=0.06, \delta_{1}=0.09, \delta_{2}=0.6, \sigma_{1}=0.0002, \sigma_{2}=$ $0.00008, \beta_{1}=0.000567, \beta_{2}=0.00764, \gamma_{1}=0.006, \gamma_{1}=0.6, C_{n q m e l}=0.0021, C_{n q m i l}=0.0012, C_{l e l}=0.0041$, $C_{l i l}=0.0032, n_{a}=2.5, n_{b}=1.6, T_{a}=1.8, T_{b}=1.5, e_{l n q}=0.09$ and initial values $S_{l}(0)=400, S_{q m}(0)=230$, $I_{l}(0)=280, E_{l}(0)=380, E_{q m}(0)=210, I_{q m}(0)=150, R(0)=140, S_{n q m}(0)=200, E_{n q m}(0)=160$, $I_{n q m}(0)=80, R_{0}=0.6124$.

We have calculated the reproduction number $\left(R_{0}\right)$ for each set to study the global stability of disease free equilibrium and endemic equilibrium of the system. If $R_{0}<1$, then disease free equilibrium is globally asymptomatically stable; if $R_{0}>1$, then endemic equilibrium is globally asymptomatically stable and disease free equilibrium is globally asymptomatically unstable [17]. With help of the reproduction number, we are able to predict the nature of the disease in the compartment.

The variation in infection rate with respect to time (Figure 2) indicates the volatile scenario of the dynamics of infection as we observed in India. As the reproduction number $R_{0}=4.0128>1$, hence the disease free equilibrium is globally asymptomatically unstable and endemic equilibrium is globally asymptomatically stable. In this case, there is a growth in the coronavirusly affected individuals in non-quarantined compartment; while after a peak, the rate of infection in the local population slows 
down and it results in a decrease in the quantity of the local infected population. The nature of graphical results 2 of this set of parameters and initial guesses match the results given by Kankan Sarkar et al. [20] who has taken integer-order model as the base of their study.

In Fig. 3, the steady growth in all infected classes has place which results in the constant rate of infection. The continuous growth in the set of recovered individuals is also observed. The reproduction number of the data of Fig. 3 is $R_{0}=3.8247>1$, so the endemic equilibrium is globally asymptomatically stable as shown. Hence behaviour of the disease will stabilise at a certain level and the flow of infection will increase. This scenario will not be some what suitable to avoid the pandemic situation. Biswas Sudhanshu Kumar, et al. [21] and Kaustuv chatterjee et al. [22] have analysed different mathematical models for COVID-19 impact and prediction. The graphical results given by them coincide with the presented results of Fig. 3 of this work. The present results focus broadly on the real scenario of the pandemic in the containment zones of India.

The estimated data of Fig. 4 gives reproduction number as $R_{0}=0.6124<1$. The disease free equilibrium is globally asymptomatically stable. The figures also demonstrate that there is considerable downfall in the number of infected population over the period of time. In this case, we have proposed the set of parameters to decide the control strategy. Since, the reproduction number is less than a unit, here, the disease will be under control after some period. The scenario will be some what suitable to avoid the pandemic situation.

\section{Conclusions}

We have proposed a novel fractional-order mathematical model to investigate the efficacy of quarantine as a containment measure. With the posed assumptions, the model successfully attempts to analyse the current scenario as a wider picture and to decide the control strategy. The existence and uniqueness of the proposed model has been confirmed by applying fixed point theorem.

The following distinctive features of our model are:

1. We have considered the immigrated population as a source of infection. This has also been observed in the real world scenario during early stages of the pandemic.

2. We have also considered the asymptomatic state of the disease of some individuals. Interactions between asymptomatic (non-quarantined and local) persons can further provoke the coronavirus transmission.

3. We have taken into account the fact that nobody in the exposed class will be infected owing to differential viral load. Hence, they directly move to the recovered class.

These features have been observed all over India in this pandemic situation of COVID-19.

While computing the reproduction number, not only the infected but also the exposed individuals contribute to secondary infection. This assumes special importance in transmission dynamics of the disease. The authors have kept this into account while making certain conclusions.

For numerical simulation of the model, RK4 and generalised Euler method (GEM) are applied for integer order with the help of MATLAB and the results obtained by applying both methods matching those for integer order. Further, we extended the numerical simulation for fractional order by applying generalised Euler method (GEM).

If we take following precautions then the disease will be controlled and eliminated from the population. First of all, we should restrict the involvement of immigrated population directly with local population by restricting them to compulsory quarantine. Numerical simulations in graphical form predict that a significant cause of spread of infection is due to the non-quarantined asymptomatic population. So the rate of transfer of infection to the local exposed individuals should be minimised. Further, to identify the infected individuals from non-quarantined asymptomatic individuals, the random testing has to be conducted in the containment areas. To increase the direct recovery rate from the local exposed population and the non-quarantined immigrated population, the immunity power should be enhanced by some appropriate medical guidelines, so that the recovery rate at these stages 
will increase and the chances of spread of disease will minimise. To bring more accuracy in the model and to decide the strategy to control the disease, we can vary fractional-order components. Fractionalorder model carries memory effects. It has found to be more effective than integer-order model. In the numerical analysis, if the reproduction number is greater than a unit, then it is observed that the fractional-order component is directly proportional to the infection rate and inversely with the recovery rate. It is reverse when the reproduction number is less than a unit. As the fractional-order model possess non-local dynamics and has long memory, it gives real behaviour of the nature of COVID-19 rather than ideal behaviour. In such complex study of the disease, we get a wide platform through the fractional-order model than integer-order one. So fractional-order model may help better than integerorder model to choose from the various patterns in disease progression in a certain containment area. Finally, we may conclude that the present fractional-order model has given wide platform to decide the future strategy for the control of COVID-19 in India.

[1] World Health Organization. Pneumonia of unknown cause - China, Emergenciespreparedness, response, Disease outbreak news. World Health Organization(WHO).

https://www. who.int/csr/don/05-january-2020-pneumonia-of-unkown-cause-china/en/ (2020).

[2] World Health Organization. Laboratory testing for 2019 novel coronavirus (2019-nCoV) in suspected human cases. World Health Organization(WHO).

https://www . who. int/health-topics/coronavirus/laboratory-diagnostics-for-novel-coronavirus (2020).

[3] Lin Q., Zhao S., Gao D., Lou Y., Yang S., Musa S. S., Wang M. H., Cai Y., Wang W., Yang L., He D. A conceptual model for the coronavirus disease 2019 (COVID-19) outbreak in Wuhan, China with individual reaction and governmental action. International journal of infectious diseases. 93, 211-216 (2020).

[4] Wuhan Municipal Health Commission, China. New press and situation reports of the pneumonia caused by novel coronavirus from December 31, 2019 to January 21, 2020 released by the Wuhan municipal health commission, China (2020). http://wjw. wuhan.gov.cn/front/web/list2nd/no/710

[5] Rothana H. A., Byrareddy S. N. The epidemiology and pathogenesis of coronavirus disease (COVID-19) outbreak. Journal of Autoimmunity. 109, 102433 (2020).

[6] https://www.mygov.in/covid-19, June 06, 2020.

[7] Victor A. Mathematical predictions for COVID-19 as a global pandemic. Available at SSRN: https://ssrn. com/abstract=3555879 (2020).

[8] Ivorra B., Ferrández M. R., Vela-Pérez M., Ramos A. M. Mathematical modeling of the spread of the coronavirus disease 2019 (COVID-19) taking into account the undetected infections. The case of China. Communication Nonlinear Science and Numerical Simulations. 88, 205303 (2020).

[9] Tuite A. R., Fisman D. N., Greer A. L. Mathematical modelling of COVID-19 transmission and mitigation strategies in the population of Ontario, Canada. medRxiv (2020).

[10] Chen T.-M., Rui J., Wang Q. P., Zhao Z.-Y., Cui J.-A., Yin L. A mathematical model for simulating the phase-based transmissibility of a novel coronavirus. Infectious Diseases of Poverty. 9, Article number: 24 (2020).

[11] Samko S. G., Kilbas A. A., Marichev Q. I. Fractional Integrals and Derivatives Theory and Applications. Gorden and Breach, New York (1993).

[12] Podlubny I. Fractional Differential Equation. Academic Press, New York (1999).

[13] Pawar D. D., Patil W. D., Raut D. K. Numerical solution of fractional order mathematical model of drug resistant tuberculosis with two line treatment. Journal Mathematics and Computational Science. 10 (2), 262-276 (2019).

[14] Kumar D., Singh J., Qurashi M. A., Baleanu D. A new fractional SIRS-SI malaria disease model with application of vaccines, antimalarial drugs, and spraying. Advances in Difference Equations. 2019, Article number: 278 (2019).

[15] Pawar D. D., Patil W. D., Raut D. K. Analysis of malaria dynamics using its fractional order mathematical model. Journal of Applied Mathematics and Informatics. 39 (1-2), 197-214 (2021). 
[16] Shaikh A. S., Shaikh I. N., Nisar K. S. A mathematical model of COVID-19 using fractional derivative: outbreak in India with dynamics of transmission and control. Advances in Difference Equations. 2020, $373(2020)$.

[17] Khan M. A., Ullah S., Farooq M. A new fractional model for tuberculosis with relapse via AtanganaBaleanu derivative. Chaos, Solitons \& Fractals. 116, 227-238 (2018).

[18] Khan M. A., Atangana A. Modeling the dynamics of novel coronavirus (2019-nCov) with fractional derivative. Alexandria Engineering Journal. 59 (4), 2379-2389 (2020).

[19] Mohamed A. S., Mahmoud R. A. Picard, Adomian and predictor corrector methods for an initial value problem of arbitrary (fractional) orders differential equation. Journal of the Egyptian Mathematical Society. $24(2), 165-170$ (2016).

[20] Sarkar K., Khajanchi S., Nieto J. J. Modeling and forecasting the COVID-19 pandemic in India. Chaos, Solitons and Fractals. 139, 110049 (2020).

[21] Biswas S. K., Ghosh J. K., Sarkar S. COVID-19 pandemic in India: a mathematical model study. Nonlinear dynamics. 102 (1), 537-553 (2020).

[22] Chatterjee K., Chatterjee K., Yadav A. K., Subramanian S. Healthcare impact of COVID-19 epidemic in India: A stochastic mathematical model. Medical Journal Armed Forces India. 76 (2), 147-155 (2020).

\title{
Математична модель дробового порядку для аналізу впливу карантину на поширення COVID-19 в Індії
}

\author{
Павар Д. Д. ${ }^{1}$, Патил В. Д. ${ }^{2}$, Раут Д. К. ${ }^{3}$ \\ ${ }^{1}$ Школа математичних наук, \\ Університет Свамі Рамананда Тірта Маратвади, Нандед-431606, Індія \\ ${ }^{2}$ Кафедра прикладної математики, \\ Інженерний коледж А. С. Патил, Наві Мумбаї-410210, Індія \\ ${ }^{3}$ Кафедра математики, \\ Шиваджі Махавідялая, Ренапур, Латур-41352\%, Індія
}

\begin{abstract}
Вперше про спалах нової коронавірусної інфекції повідомили у місті Ухань, Китай, у грудні 2019 року. В Індії про перший випадок було повідомлено 30 січня 2020 року, це була особа з історією переміщень до інфікованої країни. Беручи до уваги факт густонаселеної та диверсифікованої країни, такої як Індія, запропоновано нову математичну модель дробового порядку, щоб визначити динаміку поширення коронавірусної хвороби (COVID-19) та стратегію її контролю в Індії. Класична модель SEIR застосована до трьох секцій населення, а саме: мігранти на карантині, безсимптомні мігранти не переміщені на карантин та місцеве населення, яке уряд Індії піддав блокуванню в зоні стримування для запобігання розповсюдженню хвороби в Індії. Також враховано фізичну взаємодію між ними для оцінки динаміки поширення коронавірусу. Встановлено базове репродуктивне число $\left(R_{0}\right)$ для визначення заражуваності COVID-19. Чисельне моделювання проведено за допомогою узагальненого методу Ейлера. Щоб перевірити актуальність нашого аналізу, ми дослідили деякі чисельні моделювання для різного дробового порядку, змінюючи значення параметрів за допомогою MATLAB, щоб дослідження відповідало реалістичному сценарію пандемії.
\end{abstract}

Ключові слова: COVID-19, епідемія, математична модель дробового порядку (ММДБ), число відтворення, узагальнений метод Ейлера (УМЕ). 